\title{
Modification of Ion-exchange Membrane Surface by Plasma Processes V. Surface Modification of Nafion by 3-(2-aminoethyl)aminopropyltrimethoxysilane
}

\author{
Zempachi OGUMI*, Yoshiharu UCHIMOTO, Kazuaki YASUDA, \\ Tutomu YOSHIDA and Zen-ichiro TAKEHARA
}

Received January 14, 1992 ; Accepted March 13, 1992

\begin{abstract}
The monovalent cation perm-selectivity of Nafion 117 was enhanced by depositing on its surface an ultra-thin anionic exchange layer for use as separators of electrochemical systens. After a Nafion 117 sheet was set on an RF electrode and sputtered with an oxygen or argon plasma in order to produce radical sites on the Nafion, 4-vinylpyridine or 3-(2-aminoethy1)aminopropyl-trimethoxysilane vapor was introduced into a reactor to react with the radical sites. The influences of sputtering gas and magnitude of RF power on the perm-selectivity were investigated.
\end{abstract}

\section{INTRODUCTTON}

Recently, ion-exchange membranes have received considerable attention as separators between compartments of electrochemical systems, such as brine electrolyzers ${ }^{1)}$, water electrolyzers ${ }^{2}$, organic electrolyzers ${ }^{3,4)}$, redox-flow batteries ${ }^{5)}$, sensors ${ }^{6)}$, and fuel cel1s ${ }^{7)}$. Although ion-exchange membranes have a high selectivity of counter-ions over co-ions, their selectivity among different counter-ions is generally low. The performance of the redox-flow batteries and brine electrolyzers is strongly dependent on the permselectivity among ions of the same polarity. Thus, the development of redoxflow batteries and brine electrolyzers would be greatly aided by the availability of cation-exchange membranes having a high monovalent ion perm-selectivity.

We have investigated the surface modifi-

Department of Industrial Chemistry, Faculty of Engineering, Kyoto University, Yoshida, Sakyo-ku, Kyoto 606-J1

Key words: surface modification, ionexchange membrane, plasma process cation of a cation-exchange membrane by utilizing glow-discharge plasma processes in order to enhance the perm-selectivity among different counter ions. ${ }^{8-12)}$ The monovalent cation perm-selectivity of a perfluorinated cation-exchange membrane, Nafion (Du Pont), was enhanced by depositing on its surface an ultra-thin anionexchange layer containing pyridyl or quaternarized pyridyl and/or amino groups. The principle of the enhancement of monovalent cation perm-selectivity is shown in Fig. 1. A thin layer of anion exchanger is deposited on the surface of a cationexchange membrane, Nafion. On account of electrostatic repulsion from the fixed anionic groups in the cation-exchange membrane, anions can not be transported through the membrane. Similarly, the transport of monovalent cations and multivalent cations also is suppressed by the electrostatic repulsion from the fixed cationic groups in the thin anion-exchange layer on the surface of the cationexchange membrane. However, since the repulsion for monovalent ions from the fixed cations in the thin anion-exchange 


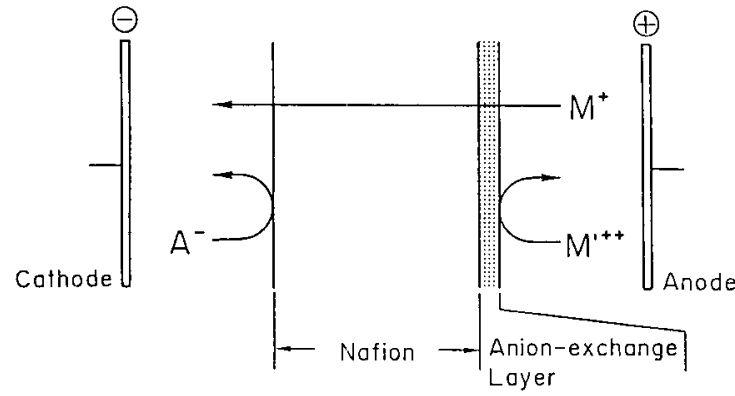

Fig. 1. Principle of the enhancement of monovalent cation perm-selectivity through a cation-exchange membrane.

layer is weaker than that for multivalent ions, monovalent ions can be transported through the anion-exchange layer much more easily than can multivalent ions. 5)

In previous study, ${ }^{12)}$ a novel method of plasma-induced surface modification technique was proposed for the enhancement of monovalent cation perm-selectivity of Nafion using 4-vinylpyridine as a source of pyridyl and/or amino groups. First, radical sites were produces by sputtering on the surface of Nafion. Next, 4-vinylpyridine was introduced into a reactor to react with radical sites.

In the present paper, the influences of sputtering gas composition and an $R F$ power of sputtering on the monovalent cation perm-selectivity were investigated.

\section{EXPERTMENTAL}

\subsection{Plasma treatment}

A schematic diagram of an apparatus for plasma-induced surface modification is shown in Fig. 2. The system consisted of a cylindrical glass reactor $(30 \mathrm{~cm}$ in height and $9 \mathrm{~cm}$ in diameter) equipped with two inner disk electrodes, two gas inlets, a Pirani gauge, and an RF supply (13.56 $\mathrm{MHz}$ ) with an impedance matching network. This reactor was connected to a vacuum system comprising of a mechanical booster pump and a rotary pump. A Nafion 117 sheet was fixed on an RF electrode and sputtered by an oxygen or argon plasma at various flow rates and $R F$ powers in order

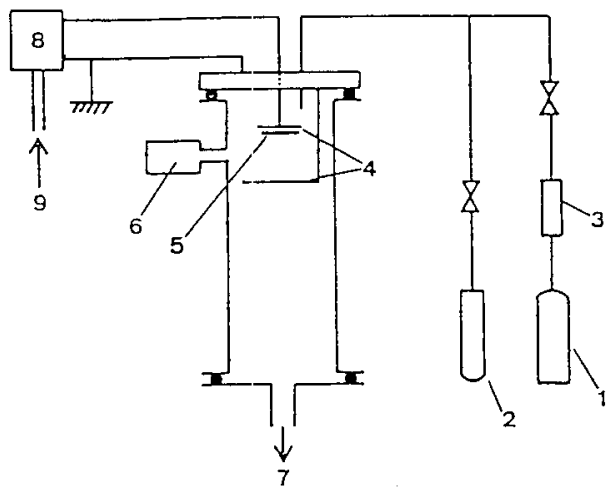

Fig. 2. A schematic diagram of an apparatus for plasma-induced surface modification. 1, Ar or $\mathrm{O}_{2} ; 2$, monomer; 3, flow meter; 4, parallel disk electrodes; 5, substrate; 6, Pirani gauge; 7, pumping system; 8, matching network; 9, $13.56 \mathrm{MHz}$ power supply.

to produce radical sites on the Nafion surface. After sputtering, 4-vinylpyridine or 3-(2-aminoethylaminopropy1)trimethoxysilane vapor was introduced into the reactor and reacted with the radical sites. Thus a thin layer containing pyridyl or aminc groups was formed on the Nafion.

\subsection{Quaternarization of the thin layer containing pyridyl or amino groups}

The thin layer containing pyridyl or amino groups was quaternarized by treatment with a 1 vol\% 1-bromopropane/propy1ene carbonate solution at $50^{\circ} \mathrm{C}$ for 48 h. 13) After soaking, the films were washed with propylene carbonate to remove excess 1-bromopropane. The films thus treated were then dried under reduced pressure $\left(10^{-1} \mathrm{~Pa}\right)$ in order to remove propylene carbonate.

2.3. Characterization of the surfacemodified Nafion film

Since Nafion has the least affinity for $\mathrm{Li}^{+}$among monovalent cations including proton and other alkali metal cations, 14$)$ $\mathrm{Li}^{+}$was selected to elucidate the enhancement of monovalent cation perm- 
selectivity. The perm-selectivity of plasma-modified Nafion was evaluated by $t_{\mathrm{Fe}}$ in a $\mathrm{Li}^{+}-\mathrm{Fe}^{2+}$ system. The membrane was set as a separator between two compartments of a glass cel1. Each compartment was filled with an electrolyte solution as listed in Table 1 .

Table 1. Composition of the electrolyte used for perm-selectivity measurements.

\begin{tabular}{|c|c|}
\hline Catholyte & Ar.olyte \\
\hline $0.2 \mathrm{M} \mathrm{CH}_{3} \mathrm{COOH}$ & $0.2 \mathrm{M} \quad \mathrm{CH}_{3} \mathrm{COOH}$ \\
\hline $0.2 \mathrm{M} \mathrm{CH}_{3} \mathrm{COOLi}$ & $0.2 \mathrm{M} \quad \mathrm{CH}_{3} \mathrm{COOLi}$ \\
\hline \multirow[t]{2}{*}{$0.8 \mathrm{M} \mathrm{LiCl}$} & $0.7 \mathrm{M} \quad \mathrm{LiCl}$ \\
\hline & $0.05 \mathrm{M} \mathrm{FeCl}_{2}$ \\
\hline
\end{tabular}

A measuring technique of ohmic resistance of the plasma surface-modified Nafion was described previously. 11)

\section{RESULTS AND DISCUSSION}

\subsection{Plasma-induced surface modification}

\section{of Nafion}

A Nafion 117 sheet was fixed on an RF electrode and sputtered with an oxygen or argon plasma at various flow rates and $R F$ powers in order to generate radical sites on the Nafion. After sputtering, radical sites on the argon-sputtered Nafion reacted with 4-vinylpyrid-ine or 3-(2aminoethyl)aminopropyltrimethoxysilane in
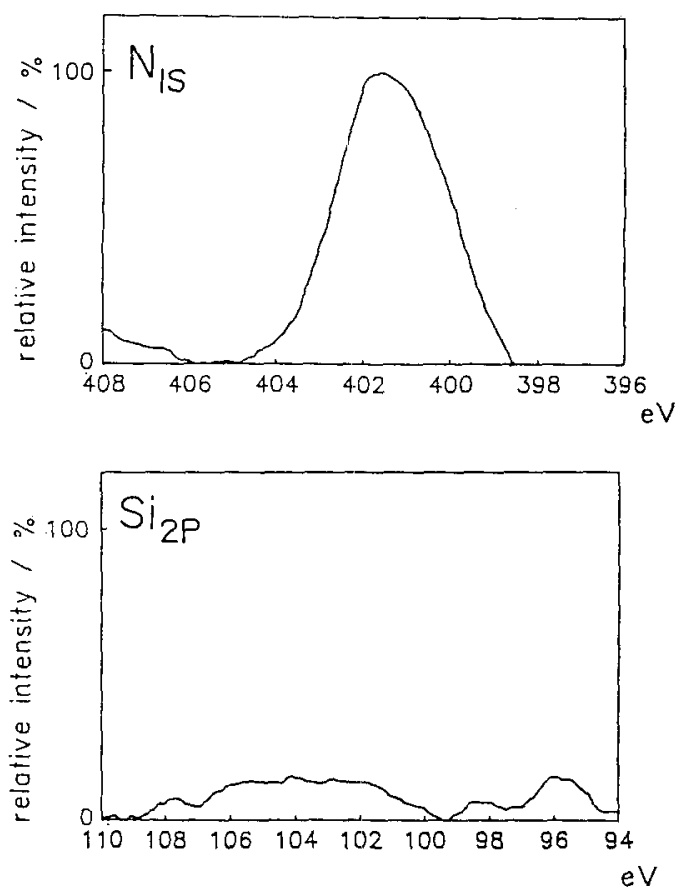

Fig. 3. $\mathrm{N}_{1 \mathrm{~s}}$ and $\mathrm{Si}_{2 \mathrm{p}}$ ESCA spectra of Nafion surface-modified with 3-(2-aminoethylaminopropyl)trimethoxysilane.

order to form a thin anionic layer on the Nafion surface. ESCA $N_{1 s}$ and $S_{2 p}$ peaks after reaction with 3-(2-aminoethy1)aminopropyltrimethoxysilane are shown in Fig. 3. These indicate that nitrogen atom was introduced on the Nafion surface. On the other hand, silicon atom was not detected on the treated Nafion. The possible reaction of 3-(2-aminoethyl)aminopropyl-

$$
\mathrm{NH}_{2}\left(\mathrm{CH}_{2}\right)_{2} \mathrm{NH}\left(\mathrm{CH}_{2}\right)_{3}-\mathrm{Si}\left(\mathrm{OCH}_{3}\right)_{3}
$$

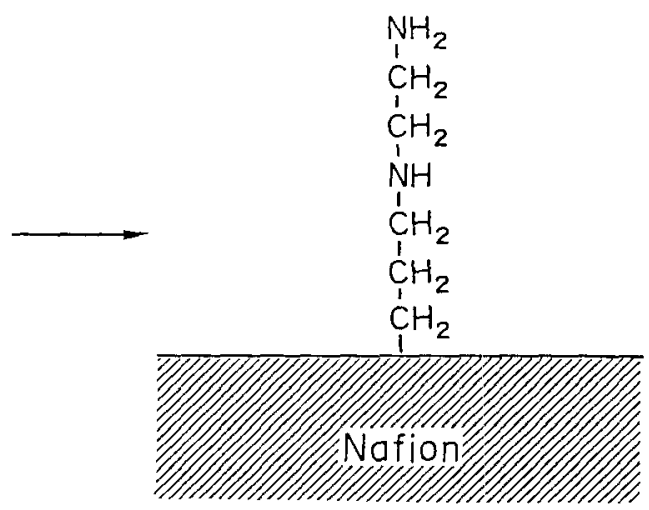

Fig. 4. Possible reaction of 3-(2-aminoethyl)aminopropyltrimethoxysilane with radical sites on Nafion. 
trimethoxysilane with radical sites on argon sputtered Nafion is illustrated in Fig. 4. Due to the weakness of Si-C bond in 3-(2-aminoethy1)aminopropyltrimethoxysilane, the bond is cleaved and $\mathrm{Si}$ containing group evaporates.

\subsection{Influence of source gas composition} on the monovalent cation perm-selectivity

The $t_{F e}$ through Nafion modified by a reaction with 4-vinylpyridine and 3-(2aminoethyl) aminopropyltrimethoxysilane

after argon sputtering is summarized in Fig. 5. Oxygen was used for the sputtering gas. The gas flow rate and sputtering pressure were kept at $10 \mathrm{~cm}^{3}(\mathrm{STP}) / \mathrm{min}$ and $67 \mathrm{~Pa}$ respectively.

The $t_{F e}$ of untreated Nafion membrane was 0.32 . These results show that ${ }^{t} \mathrm{Fe}$ for Nafion treated by plasma-induced surface modification was significantly lower than that for untreated Nafion.

Modification by a reaction with 3-(2aminoethyl)aminopropyltrimethoxysilane was more effective than that by 4-vinylpyridine. This may be ascribed to the lower Si-C bond energy than $\mathrm{C}-\mathrm{C}$. The lower bond energy facilitated a reaction of 3-(2-aminoethyl)aminopropyltrimethoxysilane with radicals, on the surface

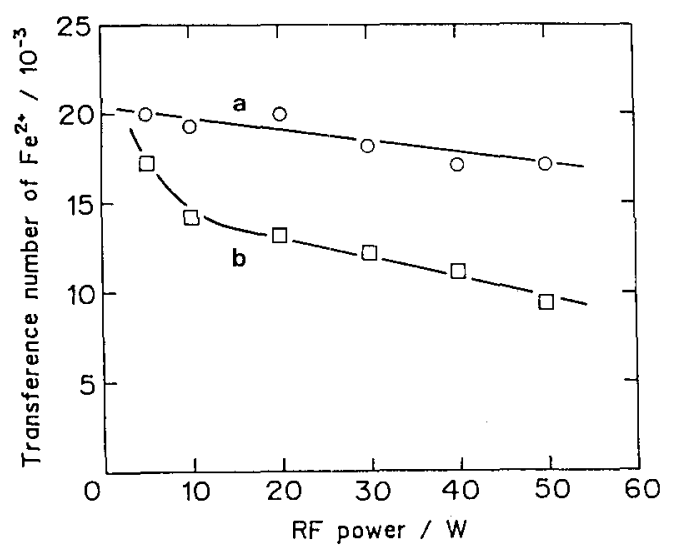

Fig. 5. Dependencies of $\mathrm{t}_{\mathrm{Fe}}$ on sputtering power.

$\mathrm{O}_{2}: 10 \mathrm{~cm}^{3}(\mathrm{STP}) / \mathrm{min}$, pressure: $67 \mathrm{~Pa}, 1$ min, (a)4-vinylpyridine, (b) 3-(2-aminoethy1)aminopropyltrimethoxysilane compared with the reaction of 4vinylpyridine; the content of fixed amino group was higher: for the former than for the latter.

Dependencies of $t_{F e}$ of the Nafion modified by 3-(2-aminoethy 1)aminopropy1trimethoxysilane on sputtering power were examined at gas flow rate of 10 $\mathrm{cm}^{3}$ (STP)/min and sputtering pressure of 67 $\mathrm{Pa}$. As shown in Fig. 6, $\mathrm{t}_{\mathrm{Fe}}$ decreased with an increase in an $\mathrm{RF}$ power. Increase in the $R F$ power lead to an increase in the concentration of reactive species in a glow region. Radical sites on a Nafion surface increased with increase in the concentration of reactive species. The large concentration of radical sites introduced on the Nafion surface treated in a high $\mathrm{RF}$ power region lead to remarkable lower:..ng $\mathrm{t}_{\mathrm{Fe}}$.

$\mathrm{t}_{\mathrm{Fe}}$ for Nafion modified by sputtering using Ar was sightly lower than that using by oxygen. Radical sites produced by ion bombardment react with not only 3(2-aminoethyl) aminopropyltrimethoxysilane but oxygen which is know as a radical scavenger. Oxygen remains in the reactor after end of sputtering. Therefore, surface density of amino groups sputtered by oxygen is lower than that by argon,

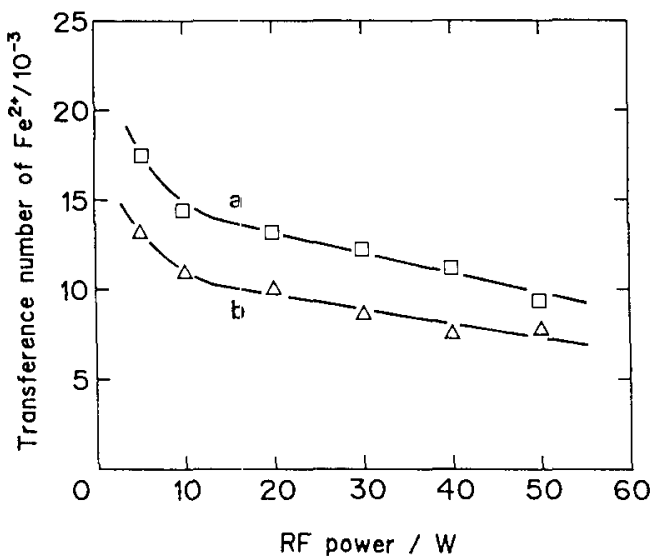

Fig. 6. Dependencies of $t_{\mathrm{Fe}}$ of the Nafion modified by 3-(2-aminoethyl)aminopropyltrimethoxysilane on sputtering power. sputtering gas (a: $\mathrm{O}_{2}, \mathrm{~b}: \mathrm{Ar}$ ): $10 \mathrm{~cm}^{3}$ (STP) /min, pressure: $67 \mathrm{~Pa}, 1 \mathrm{~min}$. 


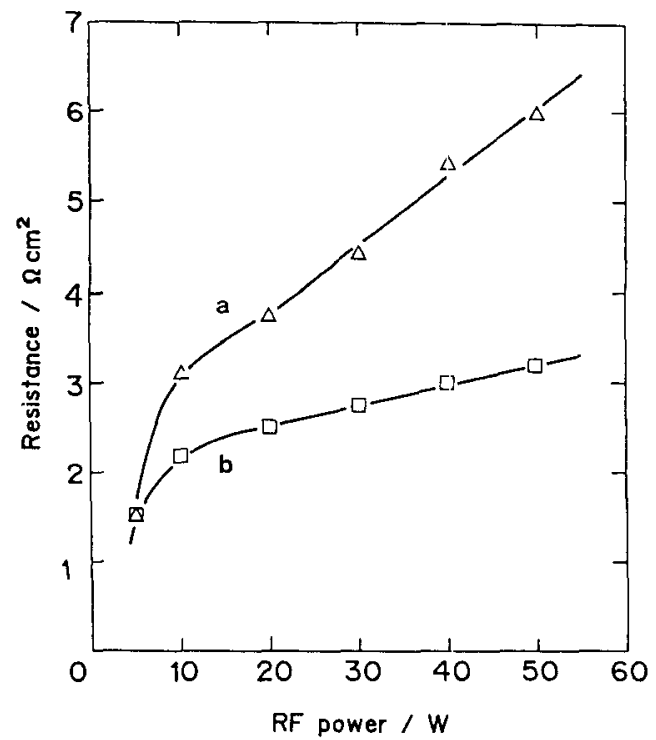

Fig. 7. Dependencies of the membrane resistance of the Nafion modified by 3-(2aminoethy 1)aminopropy 1 trimethoxysilane on sputtering power.

sputtering gas (a: $\left.\mathrm{Ar}, \mathrm{b}: \mathrm{O}_{2}\right): 10 \mathrm{~cm}^{3}$ (STP) /min, pressure: $67 \mathrm{~Pa}, 1 \mathrm{~min}$.

\section{leading to the higher $\mathrm{t}_{\mathrm{Fe}}$.}

The membrane resistance of Nafion modified by 3-(2-aminoethy1)aminopropyltrimethoxysilane is summarized in Fig. 7 . The membrane resistance increased upon increasing $\mathrm{RF}$ power. The increase in the concentration of radical sites on Nafion causes a contradicting effects; the increase of cationic group enhance the cation selectivity while its increase the membrane resistance. Optimization must be considered between two effects for the better performance of membrane permselectivity of the membrane as the separator.

\section{REFERENCES}

1) D. Bergner and K. Hannesen, Chem. Ing. Techn., 52, 413 (1980).

2) R. S. Yeo, J. McBreen, G. Kissel, F. Klesa, and S. Srinivasan, J. Appl. Electrochem., 10, 741 (1980).

3) Z. Ogumi, T. Mizoe, Z. Chen, and Z. Takehara, Bull. Chem. Soc., Jpn., $\underline{63}, 3365$ (1990).

4) Z. Chen, Z. Ogumi, and Z. Takehara, Bu11. Chem. Soc., Jpn., 64, 1261 (1991).

5) H. Ohya, K. Emori, T. Ohto, Y. Negishi, and K. Matsumoto, Denki Kagaku, 53, 462 (1985).

6) A. B. Laconti, and H. J. Marget, J. Electrochem. Soc., 118, 506 (1971).

7) W. Paik, T. E. Springer and S. Srinivasan, J. Electrochem. Soc., 136, 644 (1989).

8) Z. Ogumi, Y. Uchimoto, M. Tsujikawa, and Z. Takehara, J. Electrochem. Soc., 136, 1247 (1989).

9) Z. Ogumi, Y. Uchimoto, M. Tsujikawa, Z. Takehara, and F.R. Foulkes, J. Electrochem. Soc., 137, 1430 (1990).

10) Z. Ogumi, Y. Uchimoto, M. Tsujikawa, and Z. Takehara, Bu11. Chem. Soc., Jpn., 2150 (1990).

11) Z. Ogumi, Y. Uchimoto, M. Tsujikawa, and Z. Takehara, J. Membrane Sci., 54, 163 (1990).

12) Y. Uchimoto, K. Yasuda, T. Yoshida, and $\mathrm{Z}$. Takehara, Submitted for publication.

13) R. M. Fouss, M. Watanabe, and B. D. Coleman, J. Polym. Sci., 35, 5 (1960).

14) H.L. Yeager and A, Steck, Anal. Chem., 51, 862 (1979). 